\author{
GeoChips for Analysis of Microbial Functional Communities \\ JOY D. VAN NOSTRAND, LIYOU WU, ZHILI HE, AND JIZHONG ZHOU \\ Institute for Environmental Genomics and Department of Botany and Microbiology; University of \\ Oklahoma, Norman, OK 73019, USA; Virtual Institute for Microbial Stress and Survival, \\ http://vimss.lbl.gov
}

\begin{abstract}
Functional gene arrays (FGA) are microarrays that contain probes for genes encoding proteins or enzymes involved in functions of interest and allow for the study of thousands of genes at one time. The most comprehensive FGA to date is the GeoChip, which contains $\sim 24,000$ probes for $\sim 10,000$ genes involved in the geochemical cycling of C, N, P, and S, as well as genes involved in metal resistance and reduction and contaminant degradation. This chapter details the methods necessary for GeoChip analysis. Methods covered include preparation of DNA (whole community genome amplification and labeling), array setup (prehybridization steps), hybridization (sample and hybridization buffers), and post hybridization steps (slide washing and array scanning).
\end{abstract}




\section{Introduction}

Microarrays are a powerful, high throughput tool that allows for the study of thousands of genes at one time. While microarrays were first designed to study individual organisms (Schena et al., 1995), their potential to study microorganisms in the environment was later proposed (Guschin et al., 1997). Several types of microarrays have since been developed to examine microbial communities. These include phylogenetic arrays composed of 16S rRNA gene probes or other conserved functional genes for examining species diversity or community composition (Small et al., 2001; Loy et al., 2002; Wilson et al., 2002), community genome arrays comprised of whole genomic DNA from microbial isolates that can be used to determine microbial identity or to screen for species of interest (Wu et al., 2004; Zhang et al., 2004, Wu et al. 2008), and functional gene arrays (FGA), which contain probes for genes encoding proteins or enzymes involved in functions of interest (Wu et al., 2001; Tiquia et al., 2004; Gentry et al., 2006; He et al., 2007). Because probes are designed for sequences with known functions, FGAs, unlike phylogenetic and community genome arrays, can provide information regarding the potential functional capabilities of microbial communities and are ideally suited for linking microbial functional structure with geochemical and other environmental processes. In addition, unlike traditional polymerase chain reaction (PCR)-based approaches, FGAs allow hundreds or thousands of genes or gene groups to be examined simultaneously without the need to design specific primers (Wu et al., 2001; Zhou and Thompson, 2002; Gentry et al., 2006; Wu et al., 2006; He et al., 2007; Wagner et al., 2007; Zhou et al., 2008). FGAs have been designed to examine specific microbial populations or processes of interest, such as $\mathrm{N}$ cycling (Wu et al., 2001; Tiquia et al., 2004), nifH diversity (Steward et al., 2004), contaminant degradation and metal resistance (Rhee et al., 2004), and acid mine drainage sites (Yin et al., 2007), among others (Gentry et al., 2006). Evaluation of FGAs have shown these arrays to be both sensitive and 
specific (Wu et al., 2001; Cho and Tiedje, 2002; Rhee et al., 2004; Tiquia et al., 2004; Wu et al., 2006; He et al., 2007; Leigh et al., 2007; Yergeau et al., 2007; Wu et al., 2008).

The most comprehensive FGA available to date is the GeoChip 2.0, which contains $\sim 24,000$ probes for genes involved in the geochemical cycling of $\mathrm{N}, \mathrm{C}$, and $\mathrm{S}$, metal reduction and resistance, and in organic contaminant degradation (He et al., 2007). The GeoChip was designed to address two of the major challenges in the use of FGAs for microbial community analysis: (i) the need for adequate oligonucleotide probe specificity for genes that have high homologies and (ii) the lack of a truly comprehensive FGA probe set (He et al., 2007). This array has been used in a variety of studies to examine the functional potential of microbial communities (RodríguezMartínez et al., 2006; Wu L. et al., 2006; He et al., 2007; Yergeau et al., 2007; Wu et al., 2008; Zhou et al., 2008; Mason et al., submitted), to probe pure culture isolates for specific gene functions (Van Nostrand et al., 2007), in stable isotope probing experiments (Leigh et al., 2007), and for the detection of microbial community RNA (Gao et al., 2007). The next generation of GeoChip (GeoChip 3.0), which has $\sim 47,000$ probes, representing 292 gene families, has been developed and is currently being tested and validated (Deng et al., unpublished data).

Another great advantage of GeoChip, and other FGAs, is the ability to customize the array to focus on functions or processes of interest to the researcher and the ability to continuously update the sequences covered on the array. Sequences that are optimal for inclusion are those that encode a key step or protein in the process of interest, are conserved but still provide enough sequence variance for probe design, and have sufficient sequences available in public databases (Gentry et al., 2006). The sequences chosen for inclusion should be carefully evaluated and tested so that only sequences with confirmed functions (either experimentally or via sequence similarity) are included.

Several software programs are available for probe design which can provide probe sequences appropriate for FGAs. However, a study by our lab suggested that there could be some issues regarding specificity of these designed probes among similar sequences (Li et al., 2005). 
As such, to provide the greatest specificity, we recommend the use of the CommOligo software for probe design ( $\mathrm{Li}$ et al., 2005; Gentry et al., 2006). Criteria for probe design and selection has been discussed in detail previously (Gentry et al., 2006; He et al., 2007). GeoChip 2.0 is comprised of 24,243 50-mer oligonucleotide probes which are contact printed onto UltraGAPS (gamma amino propyl silane) coated slides (Corning; Lowell, MA). These probes cover $>10,000$ genes in $>150$ functional groups. More information regarding the development of FGAs and the GeoChip is in Chapter 22 of this volume (Van Nostrand et al., submitted). In addition, several recent publications are available that provide more detailed information regarding the design and preparation of FGAs, including sequence selection, probe design criteria, and array printing (Bodrossy et al., 2003; Rhee et al., 2004; He et al., 2005a,b; Li et al., 2005; Gentry et al., 2006; 2007; Liebich et al., 2006; He et al., 2007). The following protocols are specific to the GeoChip, although other array platforms are available which would require use of different or modified methods.

\section{Experimental approach}

\section{Target preparation}

A detailed description of DNA extraction and purification protocols will not be described here, but as these are critical first steps in sample preparation, we felt it important to address several important issues. While many methods for DNA extraction are available, the method chosen should result in large fragments of genomic DNA as this is crucial for the whole community genome amplification step. Our lab routinely uses a freeze-grind method followed by alkaline lysis (Zhou et al., 1996; Hurt et al., 2001). A full description of this method is available at our lab's website (http://ieg.ou.edu/). The extracted DNA should be purified as soon as possible after extraction to prevent degradation. We have observed degradation of raw DNA extracts after as little as one month, even at $-20^{\circ} \mathrm{C}$. Ideally, DNA should have a 260:280 ratio $\geq$ 
1.8 and 260:230 ratio $\geq 1.7$. Gel purification of soil and sediment DNA has worked very well for our lab. A column purification kit can also be used, especially for samples with low DNA yields. While these steps can be tedious, it is critical that DNA used for hybridizations be as pure as possible; therefore, it is beneficial (both in terms of time management and cost) to spend the time necessary on DNA preparation before proceeding with subsequent steps. Any impurities remaining in the DNA can interfere with amplification, labeling, and hybridization.

\section{$\underline{\text { Amplification }}$}

The GeoChip requires 2-5 $\mu$ g of genomic DNA for hybridization. Depending on the amount of DNA available, whole genome amplification (WGA) may be required. WGA can be performed using either phage $\Phi 29$ (Dean et al., 2001; Wu et al., 2006) or Bacillus stearothermophilus DNA polymerases (Lage et al., 2003; Aviel-Ronen et al., 2006). Amplification using $\Phi 29$ (Templiphi, GE Healthcare; Piscataway, NJ) for WGA of microbial community DNA has been systematically evaluated and shown to provide sensitive (10 fg detection limit) and representative amplification $(<0.5 \%$ of amplified genes showed $>2$-fold different from unamplified) (Wu et al., 2006). The following protocol uses the Templiphi amplification kit (GE Healthcare ) and is based on a previously published protocol (Wu et al., 2006). All steps should be carried out in a laminar flow hood or PCR workstation hood.

1. Add $10 \mu \mathrm{l}$ of sample buffer (supplied with kit) to a PCR tube or micro-well plate.

2. Transfer 10-100 ng DNA to the sample buffer. The total volume of DNA added should be no more than $5 \mu$ and the sample volume should be the same for all samples. Use nuclease-free water to bring the volume up, if necessary.

3. Mix the DNA and buffer thoroughly and incubate $10 \mathrm{~min}$ at room temperature. 
4. While DNA and buffer are incubating, prepare the Templiphi premix [for each reaction: $10 \mu \mathrm{l}$ reaction buffer, $0.6 \mu \mathrm{l}$ enzyme mixture (both supplied in the kit), and single stranded binding protein (USB; Cleveland, $\mathrm{OH}$ ) and spermidine to a final concentration of $260 \mathrm{ng} \mu \mathrm{l}^{-1}$ and $0.1 \mu \mathrm{M}$, respectively.]

5. Transfer $12.85 \mu \mathrm{l}$ of the Templiphi premix to the DNA/buffer mixture (or the equivalent volume for one sample).

6. Incubate the reaction at $30{ }^{\circ} \mathrm{C}$ for 3 hours and then heat-inactivate the enzyme at $65^{\circ} \mathrm{C}$ for $10 \mathrm{~min}$.

7. To evaluate the amplification quality, run approximately $2 \mu \mathrm{l}$ of amplified product on a gel. The product should produce a smear rather than a single band.

8. Quantify the amplified DNA using a dye-binding assay, such as PicoGreen (Quant-iT ${ }^{\mathrm{TM}}$ PicoGreen ${ }^{\circledR}$ dsDNA kit; Invitrogen, Carlsbad, CA). The amplified product can not be measured using 260/280 ratios due to primers and dNTPs remaining in the sample. There should be at least $2 \mu \mathrm{g}$ of amplified DNA. If there is less than this, the amplification should be repeated.

\section{Notes}

The best amplification results will be obtained using freshly extracted, high molecular weight DNA of the highest quality obtainable. However, DNA from samples with very low biomass, limited sample size, or that would be impossible to replace may not be of optimum quality yet are important to analyze. These samples can still be amplified, but may require some additional steps. If the DNA sample is very dilute, the DNA can be concentrated so that more DNA can be added to the reaction. If no or poor amplification occurs, try decreasing the amount of sample volume used to dilute out any inhibitors that may be present. Serial dilution (2-3 dilution steps) of the sample can be used to 'wash' the DNA. This approach has been used successfully in our lab for a variety of samples. Serial dilution can also be used if the DNA quality is above the 
recommended thresholds, but the amplification results are poor. Other options that can be tried include re-precipitating the DNA (using an ethanol or isopropanol protocol) to try and remove any inhibitors, increasing amplification time or performing multiple amplifications of lowproduct samples and combining the products to increase the total amount of amplified DNA.

This is a very sensitive reaction and any contaminating DNA will be amplified. Steps to limit the amount of background DNA have been outlined in Zhang et al. (2006) and include UV irradiation of the hood and all items to be used in the protocol, including tips, tubes, pipettors, tube racks, ice and ice bucket, etc. Due to the sensitivity of this reaction, negative controls should always be run alongside the samples.

\section{Labeling}

DNA for hybridization is generally labeled using fluorescent dyes, primarily Cy5 or Cy3. The DNA can be labeled directly (dyes are directly integrated into the target DNA) or indirectly (targets are labeled after hybridization). Our lab uses a direct labeling approach which is detailed below.

1. Combine $20 \mu \mathrm{L}$ random primers (octamers, $750 \mu \mathrm{g} \mathrm{mL}{ }^{-1}$; BioPrime DNA Labeling System; Invitrogen) with 2-5 $\mu$ g DNA (amplified or unamplified).

2. If necessary, bring volume up to $35 \mu \mathrm{L}$ with water (if using amplified DNA, volume may already be larger than $35 \mu \mathrm{L}$.)

3. Incubate $5 \mathrm{~min}$ at $99.9^{\circ} \mathrm{C}$ in a thermocycler and immediately chill tubes on ice.

4. In a separate tube create a master mix sufficient for all samples (per sample: $2.5 \mu 15 \mathrm{mM}$ dNTP mix [2.5 mM dTTP], $1 \mu$ l CyDye [25 nM, Cy5-dUTP; GE Healthcare], $2 \mu 1$ Klenow [40 U $\mu \mathrm{L}^{-1}$; BioPrime DNA Labeling System, Invitrogen]). The final reaction volume should be $50 \mu \mathrm{L}$, so adjust the master mix volume with nuclease free water to obtain this volume. 
5. Add an appropriate volume of master mix to the primer DNA solution.

6. Incubate at $37^{\circ} \mathrm{C}$ for $3 \mathrm{hrs}$, followed by $3 \mathrm{~min}$ at $95^{\circ} \mathrm{C}$. Labeled DNA can be kept at 4

${ }^{\circ} \mathrm{C}$ in the thermocycler if labeling is done overnight, or proceed to purification.

7. Purify the labeled DNA using a PCR clean-up kit as per the manufacturer's directions.

Our lab uses the Qiagen QIAquick PCR purification kit (Qiagen; Valencia, CA). DNA can be eluted using water or the elution buffer supplied.

8. Check CyDye incorporation by absorbance at $550 \mathrm{~nm}$ for Cy3 or $650 \mathrm{~nm}$ for Cy5. The Nanodrop ND-1000 (Thermo Scientific; Wilmington, DE) or similar spectrophotometers require only $1 \mu \mathrm{l}$ of sample. Several measures can be used to determine incorporation efficiency. The ND-1000 provides the pmol of dye/ $\mu 1$ for each sample; a minimum dye incorporation required is $50 \mathrm{pmol}(\mathrm{pmol} / \mu \mathrm{L} *$ total $\mu \mathrm{L})$. Specific activity (SA) can be determined using two different formulas: (i) $\mathrm{SA}=($ ng of target $\mathrm{x} 1000) /($ pmol dye incorp $\mathrm{x}$ 324.5), where the SA should be $>120$. (ii) The SA can also be determined using a ratio.

The $\mathrm{A}_{260} / \mathrm{A}_{550}$ ratio for Cy3 should be between 8 and 15 , while the $\mathrm{A}_{260} / \mathrm{A}_{650}$ for Cy5 should be between 10 and 20 (Zhou and Thompson, 2004).

9. Dry the sample using a speedvac at $45^{\circ} \mathrm{C}$ for $45 \mathrm{~min}$.

10. At this point, samples can be kept at $-20^{\circ} \mathrm{C}$ until ready for hybridization.

\section{Notes}

High quality, fresh reagents should be used to insure the best possible results (Wu et al., 2001). The higher the labeling efficiency, the better the hybridization results will be. CyDyes are light sensitive and should be protected from the light as much as possible. We have stored dried, labeled products for months with no apparent loss of efficacy.

\section{Hybridization}

\section{$\underline{\text { Slide preparation }}$}


Microarray slides must be pretreated prior to hybridization. The exact protocol will vary depending upon the slide chemistry used. The following protocol is used for UltraGAPS coated slides (Corning; Lowell, MA).

1. Prepare enough prehybridization solution ( $5 \mathrm{x} \mathrm{SSC}, 0.1 \% \mathrm{SDS}, 0.1 \mathrm{mg} \mathrm{mL}^{-1} \mathrm{BSA}$ ) for the number of slides being prepared and warm to $42{ }^{\circ} \mathrm{C}$ (or the temperature used for hybridization). A coplin jar ( $50 \mathrm{~mL}$ volume, 5 slide capacity) can be used for this step.

2. Immerse array slides in the warmed prehybridization solution and incubate for 45-60 min at $42{ }^{\circ} \mathrm{C}$.

3. Transfer slides to $0.1 \mathrm{x}$ SSC and incubate at room temperature $5 \mathrm{~min}$.

4. Repeat step 3.

5. Transfer slides to room temperature DI water for $30 \mathrm{sec}$.

6. Dry slides with purified canned air.

7. Examine slides for cleanliness. If the slides do not look clean, repeat steps 3 through 6.

\section{Preparation of microarray assembly}

Because the GeoChip is sensitive to temperature variations, especially to decreases in temperature below the hybridization temperature, all samples and microarray items are heated to several degrees above the hybridization temperature prior to sample loading.

1. Preheat coverslips (Lifter slips, $22 \times 60 \mathrm{~mm}$ ), array slides, tips, hybridization chambers, and an aliquot of $3 \mathrm{x} \mathrm{SSC}$ at $60{ }^{\circ} \mathrm{C}$ for at least $20 \mathrm{~min}$ in a hybridization oven. For ease of use in subsequent steps, the microarrays, coverslips, and hybridization chambers can be preassembled prior to placement in the hybridization oven.

2. Heat a heatblock to $60^{\circ} \mathrm{C}$.

3. Set a waterbath to the appropriate hybridization temperature. 


\section{Sample preparation}

1. Prepare sufficient hybridization buffer for all of the samples ( $40 \mu \mathrm{l}$ per array; $50 \%$ formamide, 3x SSC, $0.3 \%$ SDS, $0.7 \mu \mathrm{g} \mu 1^{-1}$ herring sperm DNA, $0.85 \mathrm{mM}$ DTT).

2. Rehydrate the labeled DNA with $40 \mu \mathrm{l}$ hybridization buffer.

3. Denature hydridization solution at $95^{\circ} \mathrm{C}$ for $3-5 \mathrm{~min}$ in a thermocycler and then maintain the temperature at $60{ }^{\circ} \mathrm{C}$.

4. At this point all solutions, slides, tips, and chambers should be maintained at $60{ }^{\circ} \mathrm{C}$, until the arrays are placed into the waterbath.

5. Remove a hybridization chamber, slide, and cover slip from the heating oven and place on the $60{ }^{\circ} \mathrm{C}$ heat block.

6. Using the tips from the heating oven, add $17.5 \mu \mathrm{L}$ of hot $3 \mathrm{x}$ SSC to the two wells in the hybridization chamber.

7. Apply sample to the arrays using one of two methods:

a. Pipette the hybridization buffer onto the slide approximately $1 / 3$ the way down the microarray. Add the Lifter slip by gently leaning it onto the slide and slowly lowering it until it touches the droplet on the slide, then release. Try to avoid air bubbles when assembling the array.

b. Preassemble the array with the Lifter slip in place. Slowly pipette the entire sample solution onto the surface of the slide beginning at the edge of the Lifter slip. The solution should fill all the space between the slide and the Lifter slip by capillary action.

8. Seal the hybridization chamber and immediately immerse it in the pre-warmed waterbath.

9. Incubate over night at $42{ }^{\circ} \mathrm{C}(\sim 12-16 \mathrm{~h})$.

Notes 
While this protocol used a non-mixing hybridization, mixing during hybridization has been shown to increase sensitivity. A 3-fold increase in sensitivity was obtained for low abundance DNA using the MAUI mixer compared to non-mixed hybridization reactions (Adey et al., 2002). Several automated or semi-automated hybridization stations are available which provide mixing. In addition, there are hybridization ovens and special gaskets which allow mixing during hybridization. The use of smaller hybridization volumes has also been shown to increase sensitivity (Shalon et al., 1996).

When the GeoChip was first designed, optimal hybridization conditions were determined to be $50{ }^{\circ} \mathrm{C}$ and $50 \%$ formamide (He et al., 2007). However, subsequent experiments by our lab have shown that hybridization conditions of $42{ }^{\circ} \mathrm{C}$ and $50 \%$ formamide provided results consistent with other PCR-based methods.

\section{$\underline{\text { Posthybridization }}$}

Once hybridization is completed, the microarray must be washed to remove unbound labeled DNA and hybridization buffer components that may increase background signal. The posthybridization wash protocol may differ depending on the slide chemistry used. The following protocol is based on Corning UltraGAPS slides.

1. Immediately disassemble the chamber and remove the coverslip by immersion of the slide in $42{ }^{\circ} \mathrm{C}$ (or the temperature of hybridization) Wash Buffer I ( 1 x SSC, $0.1 \%$ SDS). Do not agitate the slides.

2. Once the coverslip falls off, transfer the slide to fresh $42{ }^{\circ} \mathrm{C}$ Wash Buffer I and incubate at $42{ }^{\circ} \mathrm{C}$ for $5 \mathrm{~min}$.

3. Transfer slides to room temperature Wash Buffer II ( $0.1 \times$ SSC, $0.1 \%$ SDS) and incubate with gentle shaking for 5 min.

4. Repeat step 3 . 
5. Transfer slides to Wash Buffer III $(0.1 \mathrm{x}$ SSC $)$ and incubate with gentle shaking for 1 $\min$.

6. Repeat step 5 five times, for a total of 6 , one minute washes.

7. Transfer slides to Wash Buffer IV (0.01x SSC) for $10 \mathrm{sec}$.

8. Dry slides using purified canned air.

\section{Notes}

To reduce handling time of the slides at room temperature after hybridization, take out only one hybridization chamber at a time from the water bath.

Completed arrays should be protected from the light until imaged. A black or foil wrapped slide box works well. Imaging should be done within a few hours of removing the arrays from the hybridization chamber to minimize loss of signal.

\section{Data acquisition and preprocessing}

Scanner settings will depend upon the fluorescent dye used. This protocol will detail settings for cyanine dyes.

1. The arrays should be imaged with a laser scanner using wavelengths appropriate to the dyes used, for example $630 \mathrm{~nm}$ for Cy-5 and $543 \mathrm{~nm}$ for Cy-3.

2. Use a prescan setting with a low resolution $(30-50 \mu \mathrm{m})$ to determine the appropriate photomultiplier tube (PMT) gain (\%) and the laser power (\%) settings. The settings should provide maximum signal intensity without saturating the spots.

3. Once appropriate settings have been determined, scan the array using a higher resolution $(5-10 \mu \mathrm{m})$.

4. The scanned image can then be analyzed using a variety of array analysis software, including ArrayStar (DNAStar, Madison, WI), GenePix Pro (Molecular Devices, 
Sunnyvale, CA), GeneSpotter (MicroDiscovery, San Diego, CA), GeneChip (Affymetrix, Santa Clara, CA) and ImaGene (BioDiscovery, El Segundo, CA).

\section{Notes}

While increasing the PMT increases signal intensity, this also increases background. The hybridization signal can be photobleached, so the number of scans should be limited. The hybridization quality should be evaluated both during scanning (e.g., presence of positive control spots, even hybridization signals across the array, minimal background intensity) and after image analysis (e.g., presence of weak or poor spots). Several sources are available that provide more information regarding image preprocessing and analysis (Zhou and Thompson, 2004; He et al., 2007; Gentry et al., 2007).

\section{$\underline{\text { Solutions and materials }}$}

General laboratory supplies and equipment required:

Pipettes (with appropriate tips), $0.2 \mathrm{~mL}$ PCR tubes, $1.8 \mathrm{~mL}$ microcentrifuge tubes, thermocycler, water bath, heatblock, gel electrophoresis unit (with appropriate agarose, buffers, and staining supplies), ice bucket, nuclease-free or PCR quality water, Coplin jar or similar container

\section{Specific/special equipment required:}

Laminar flow hood/PCR workstation (e.g., AirClean 600 PCR Workstation; AirClean Systems, Raleigh, NC)

Fluorescence reader (e.g., FLUOstar OPTIMA; BMG Labtech, Durham, NC)

Spectrophotometer (e.g., NanoDrop-1000; NanoDrop Technologies, Wilmington, DE)

SpeedVac (e.g., SPD 1010 SpeedVac system; Thermo Savant, Waltham, MA)

Hybridization oven (e.g., PersonalHyb Hybridization Oven; Strategene, La Jolla, CA)

Hybridization chambers (product number 2551; Corning, Lowell, MA) 
Lifter slips (22 x 60 mm; product number 100499-610; VWR, West Chester, PA)

Purified canned air (e.g., Whoosh Duster; product number 16650-027; VWR)

Microarray scanner (e.g., ProScan Array; Perkin Elmer, Waltham, Massachusetts)

Microarray analysis software (e.g., Imagene 6.1.0; BioDiscovery, El Secundo, CA)

\section{Reagents required for amplification:}

illustra Templiphi amplification kit (product number 25-6400-50; GE Healthcare, Piscataway, NJ)

Single-stranded binding protein (SSB, product number 70032Z; USB, Cleveland, Ohio)

Ultrapure spermidine (product number 21760; USB)

Quant-iT PicoGreen dsDNA reagent (product number P11495; Invitrogen, Carlsbad, CA)

Reagents required for labeling:

Cy5-dUTP (product number PA55022 or PA55322; GE Healthcare)

BioPrime DNA labeling system (for Klenow and Random primers; product number 18094-011; Invitrogen)

dNTPs (product number 10297-018; Invitrogen)

QIAquick PCR purification kit (product number 28106; Qiagen, Valencia, CA)

\section{Reagents required for hybridizations:}

\section{For buffers:}

20x SSC buffer (3M NaCl, 0.3M sodium citrate; product number 100514-344; VWR)

10\% sodium dodecyl sulfate (SDS; product number 12001-392; VWR)

Omnipure bovine albumin (BSA) (product number EM-2930; VWR)

Ultrapure formamide (product number 15515-026; Invitrogen)

Ultrapure herring sperm DNA (product number 15634-017; Invitrogen) 
Dithiothreitol (DTT; product number PI20291; VWR)

\author{
Buffer recipes: \\ Prehybridization buffer (5x SSC, $0.1 \%$ SDS, $\left.1 \mathrm{mg} \mathrm{mL}^{-1} \mathrm{BSA}\right)$ \\ Hybridization buffer (40 $\mu \mathrm{L}$ per sample; $50 \%$ formamide, $3 x \mathrm{SSC}, 0.3 \% \mathrm{SDS} ; 0.7 \mathrm{mg} \mathrm{mL}^{-1}$ \\ herring sperm DNA, $0.85 \mathrm{mM}$ DTT) \\ Wash buffer I (1x SSC, $0.1 \%$ SDS) \\ Wash buffer II (0.1x SSC, $0.1 \%$ SDS) \\ Wash buffer III (0.1x SSC) \\ Wash buffer IV (0.01x SSC)
}

\title{
Time considerations
}

The amplification reaction can be completed in one day (5-6 h total). Reaction set-up, including UV irradiation and preparation of hood, takes from $30 \mathrm{~min}$ to $1 \mathrm{~h}$. Post-amplification quality checks (gel electrophoresis and PicoGreen assay) take approximately $1 \mathrm{~h}$. Once amplification has been confirmed, the labeling reaction can be done overnight ( $\sim 3 \mathrm{~h}$ total). Approximately $30 \mathrm{~min}$ will be required for labeling reaction set up. An additional $2 \mathrm{~h}$ will be required afterwards for purification, quality control, and drying of samples. Preparations for hybridization take approximately 2-3 h, including preheating solutions and equipment, prehybridization incubations, and preheating of arrays and chambers. It is convenient to prepare the microarrays at the end of the day so that hybridizations occur overnight (12-16 h). Buffers for rinsing can be pre-heated overnight so that they are ready to use immediately once hybridizations are completed. Post-hybridization washes take $30 \mathrm{~min}$ to $1 \mathrm{~h}$, depending on the number of arrays. Scanning generally takes 5-10 min per array, depending on the resolution and the number of dyes used. 


\section{Troubleshooting}

The most important step for successful hybridizations is to make sure the starting DNA quality is optimal. In addition, the sample quality should be evaluated at each step to determine whether to proceed. Poor amplifications are often due to inhibitors present in the sample so reducing the amount of DNA added or performing a serial dilution can often solve this problem. Low labeling efficiency may be due to poor amplification results or the use of older reagents.

Hybridization temperature or the concentration of formamide can be varied to modify stringency and specificity. Each percent of formamide is equivalent to an increase of $0.6{ }^{\circ} \mathrm{C}$. Our lab has observed that a hybridization range of $42-50{ }^{\circ} \mathrm{C}$ and $50 \%$ formamide provides accurate and specific hybridization results.

Making sure the arrays are clean after prehybridization, preventing bubble formation when setting up arrays, and thorough rinsing of arrays after hybridization will minimize background intensities, although the use of community DNA tends to result in a "dirtier" array than pure culture DNA. The presence of a high amount of atmospheric ozone can interfere with Cy-dye fluorescence (Branham et al., 2007).

\section{Research Needs}

Several challenges still exist for microarray analysis including quality of nucleic acids, specificity, sensitivity, and quantitative ability of microarrays. DNA quality and purity is critical to subsequent steps, but currently the most effective methods are also the most time consuming so more efficient, higher throughput purification methods are needed. Advances in probe design criteria, slide chemistry, and printing technology could help improve the specificity of arrays. More sensitive signal detection methods and new labeling methods (more sensitive dyes) would increase array sensitivity. Finally, while several studies have shown that FGAs can be quantitatively accurate, methods to distinguish between signal intensity changes owing to gene abundance or from sequence divergence need to be developed. 


\section{Acknowledgement}

The efforts for preparing this chapter were supported by the Virtual Institute for Microbial Stress and Survival (http://VIMSS.lbl.gov) supported by the U. S. Department of Energy, Office of Science, Office of Biological and Environmental Research, Genomics Program:GTL through contract DE-AC02-05CH11231 between Lawrence Berkeley National Laboratory and the U. S. Department of Energy, Environmental Remediation Science Program (ERSP), Office of Biological and Environmental Research, Office of Science, and Oklahoma Applied Research Support (OARS), Oklahoma Center for the Advancement of Science and Technology (OCAST), the State of Oklahoma through the Project AR062-034.

\section{References}

Adey NB, Lei M, Howard MT, Jenson JB, Mayo DA, Butel DL, Coffin SC, Moyer TC, Slade DE, Spute MK, Hancock AM, Eisenhohoffer GT, Dalley BK, McNeely MR (2002) Gains in sensitivity with a device that mixes microarray hybridization solution in a 25 - $\mu \mathrm{m}$-think chamber. Anal Chem 74:6413-6417

Aviel-Ronen S, Zhu CQ, Coe BP, Liu N, Watson SK, Lam WL, Tsao MS (2006) Large fragment Bst DNA polymerase for whole genome amplification of DNA from formalin-fixed paraffinembedded tissues. BMC Genomics 7:312-321

Branham WS Melvin CD, Han T, Desai1 VG, Moland CL, Scully AT, Fuscoe JC (2007) Elimination of laboratory ozone leads to a dramatic improvement in the reproducibility of microarray gene expression measurements. BMC Biotechnol 7:8-15

Bodrossy L, Stralis-Pavese N, Murrell JC, Radajewski S, Weilharter A, Sessitsch A (2003) Development and validation of a diagnostic microbial microarray for methanotrophs. Environ Microbiol 5:566-582 
Cho JC, Tiedje JM (2002) Quantitative detection of microbial genes by using DNA microarrays. Appl Environ Microbiol 58:1425-1430

Dean FB, Nelson JR, Giesler TL, Lasken RS (2001) Rapid Amplification of Plasmid and Phage DNA Using Phi29 DNA Polymerase and Multiply-Primed Rolling Circle Amplification. Genome Res 11: 1095-1099

Gao H, Yang ZK, Gentry TJ, Wu L, Schadt CW, Zhou J (2007) Microarray-based analysis of microbial community RNAs by whole-community RNA amplification. Appl Environ Microbiol $73: 563-571$

Gentry TJ, Wickham GS, Schadt CW, He Z, Zhou J (2006) Microarray application in microbial ecology research. Microbial Ecol 52:159-175

Gentry TJ, Schadt CW, He Z, Zhou J (2007) Functional gene arrays for microbial community analysis. In: Hurst CJ, Crawford RL, Garland JL, Lipson DA, Mills AL, Ststzenbach LD (eds) Manual of environmental microbiology, $3^{\text {rd }}$ edn. ASM Press, Washington DC, pp 1052-1062

Guschin DY, Mobarry BK, Proudnikov D, Stahl DA, Rittmann BE, Mirzabekov AD (1997) Oligonucleotide microchips as genosensors for determinative and environmental studies in microbiology. Appl Environ Microbiol 63:2397-2402

He Z. Wu L, Fields MW, Zhou J (2005a) Use of microarrays with different probe sizes for monitoring gene expression. Appl Environ Microbiol 71:5154-5162

He Z, Wu LY, Li XY, Fields MW, Zhou JZ (2005b) Empirical establishment of oligonucleotide probe design criteria. Appl Environ Microbiol 71:3753-3760

He Z, Gentry TJ, Schadt CW, Wu L, Liebich J, Chong SC, Huang Z, Wu W, Gu B, Jardine P, Criddle C, Zhou J (2007) GeoChip: a comprehensive microarray for investigating biogeochemical, ecological and environmental processes. ISME J 1:67-77 
Hurt RA, Qiu X, Wu L, Roh Y, Palumbo AV, Tiedje JM, Zhou Z (2001) Simultaneous recovery of RNA and DNA from soils and sediments. Appl Environ Microbiol 67:4495-4503

Lage JM, Leamon JH, Pejovic T, Hamann S, Lacey M, Dillon D, Segraves R, Vossbrinck B, Gonzalez A, Pinkel D, Albertson DG, Costa J, Lizardi PM (2003) Whole genome analysis of genetic alterations in small DNA samples using hyperbranched strand displacement amplification and array-CGH. Genome Res 13:294-307

Leigh MB, Pellizari VH, Uhlík O, Sutka R, Rodrigues J, Ostrom NE, Zhou J, Tiedje JM (2007) Biphenyl-utilizing bacteria and their functional genes in a pine root zone contaminated with polychlorinated biphenyls (PCBs). ISME J 1:134-148

Li X, He Z, Zhou J (2005) Selection of optimal oligonucleothide probes for microarrays using multiple criteris, global alignment and parameter estimation. Nucleic Acids Res 33:6114-6123

Liebich J, Schadt CW, Chong SC, He Z, Rhee SK, Zhou J (2006) Improvement of oligonucleotide probe design criteria for functional gene microarrays in environmental applications. Appl. Environ. Microbiol. 72:1688-1691

Loy A, Lehner A, Lee N, Adamczyk, Meier H, Ernst J, Schleifer KH, Wagner W (2002) Oligonucleotide microarray for 16S rRNA gene-based detection of all recognized lineages of sulfate-reducing prokaryotes in the environment. Appl Environ Micrbiol 68:5064-6081 Mason OU, Nakagawa T, Rosner M, Van Nostrand JD, Zhou J, Maruyama A, Fisk MR, Giovannoni SJ, the Integrated Ocean Drilling Program Expeditions 304/305 Science Party (Submitted) Hydrocarbon utilizing prokaryotes in plutonic ocean crust sampled from the Atlantis Massif, $30^{\circ} \mathrm{N}, 42^{\circ} \mathrm{W}$ (Submitted, Science)

Rhee SK, Liu X, Wu L, Chong SC, Wan X, Zhou J (2004) Detection of genes involved in biodegradation and biotransformation in microbial communities by using 50-mer oligonucleotide microarrays. Appl Environ Microbiol 70:4303-4317 
Rodríguez-Martínez EM, Pérez EX, Schadt CW, Zhou J, Massol-Deyá AA (2006) Microbial diversity and bioremediation of a hydrocarbon-contaminated aquifer (vega baja, puerto rico). Int $\mathrm{J}$ Environ Res Public Health 3:292-300

Schena M, Shalon D, Davis RW, Brown PO (1995) Quantitative monitoring of gene ecpression patterns with a complementary DNA microarray. Science 270:467-470

Shalon D, Smith SJ, Brown PO (1996) A DNA microarray system for analyzing complex DNA samples using two-color fluorescent probe hybridization. Genome Res 6:639-645

Small J, Call DR, Brockman FL, Straub TM, Chandler DP (2001) Direct detection to 16S rRNA in soil extracts by using oligonucleotide microarrays. Appl Environ Microbiol 67:4708-4716

Steward GF, Jenkins BD, Ward BB, Zehr JP (2004) Development and testing of a DNA macroarray to assess nitrogenase (nifH) gene diversity. Appl Environ Microbiol 70: 1455-1465

Tiquia SM, Wu L, Chong SC, Passovets S, Xu D, Xu Ying, Zhou J (2004) Evaluation of 50-mer oligonucleotide arrays for detecting microbial populations in environmental samples. Biotechniques 36:1-8

Van Nostrand JD, Khijniak TV, Gentry TJ, Novak MT, Sowder AG, Zhou JZ, Bertsch PM, Morris PJ. 2007. Isolation and characterization of four Gram-positive nickel-tolerant microorganisms from contaminated sediments. Microb Ecol 53:670-682

Van Nostrand JD, Liang Y, He Z, Zhou J (to be submitted) Analysis of Microbial Functional Communities using GeoChips. In: Timmis KN (ed) Handbook of hydrocarbon and lipid microbiology, vol 3, Consequences of microbial interactions with hydrocarbons, oils, and lipids. Springer, New York, pp to be determined

Wagner M, Smidt H, Loy A, Zhou J (2007) Unravelling Microbial Communities with DNAMicroarrays: Challenges and Future Directions. Microbial Ecol 3:498-506 
Wilson KH, Wilson WJ, Radosevich JL, DeSantis TZ, Viswanathan VS, Kuczmarski TA, Anderson GL (2002) High-density microarray of small-subunit ribosomal DNA probes. Appl Environ Microbiol 68:2535-2541

Wu L, Thompson DK, Li G, Hurt RA, Tiedje JM, Zhou J (2001) Development and evaluation of functional gene arrays for detection of selected genes in the environment. Appl Environ Microbiol 67:5780-5790

Wu L, Thompson DK, Liu X, Fields MW, Bagwell CE, Tiedje JM, Zhou J (2004) Development and evaluation of microarray-based whole genome hybridization for detection of microorganisms within the context of environmental applications. Environ Sci Technol 38:6775-6782

Wu L, Liu X, Schadt CW, Zhou J (2006) Microarray-based analysis of submicrogram quantities of microbial community DNAs by using whole-community genome amplification. Appl Environ Microbiol 72:4931-4941

Wu L, Kellogg L, Devol AH, Tiedje JM, Zhou J (2008) Microarray-based characterization of microbial community functional structure and heterogeneity in marine sediments from the Gulf of Mexico. Appl Environ Microbiol 74:4516-4529

Yergeau E, Kang S, He Z, Zhou J, Kowalchuk GA (2007) Functional microarray analysis of nitrogen and carbon cycling genes across an Antarctic latitude transect. ISME J 1:1-17

Yin H, Cao L, Qiu G, Wang D, Kellogg L, Zhou J, Dai Z, Liu X (2007) Development and evaluation of 50-mer oligonucleotide arrays for detecting microbial populations in acid mine drainages and bioleaching systems. J Microbiol Meth 70:165-178

Zhang L, Srinivasan U, Marrs CF, Ghosh D, Gilsdorf JR, Foxman B (2004) Library on a slide for bacterial comparative genomics. BMC Microbiol 4:12-18

Zhang K, Martiny AC, Reppas NB, Barry KW, Malek J, Chisholm SW, Church GM (2006) Sequencing genomes from single cells by polymerase cloning. Nature Biotechnol 24:680-686 
Zhou J, Bruns MA, Tiedje JM (1996) DNA recovery from soils of diverse composition. Appl Environ Microbiol 62:316-322

Zhou J, Thompson DK (2002) Challenges in applying microarrays to environmental studies. Curr Opin Biotech 13:204-207

Zhou J, Thompson DK (2004) DNA Microarray Technology. In: Zhou J, Thompson DK, Xu Y, Tiedje JM (eds) Microbial functional genomics. Wiley, New Jersey, pp 141-176

Zhou J, Kang S, Schadt CW, Garten CT Jr (2008) Spatial scaling of functional gene diversity across various microbial taxa. PNAS 105:7768-7773 